\title{
Influence of the shear stress and salinity on Anammox biofilms formation: modelling results
}

Isaac Fernández ' J. I. Bravo · A. Mosquera-Corral ·

A. Pereira 'J. L. Campos ' R. Méndez '

L. F. Melo

\begin{abstract}
Anammox biomass has a long duplication time and low yield, thus the process must be operated in reactors with good sludge retention, such as biofilm systems. Therefore, it would be important to research the ability of Anammox biomass to form biofilms under different conditions. The effects of shear stress and salinity $(\mathrm{NaCl}$ and $\mathrm{CaCl}_{2}$ ) on Anammox biofilm formation were studied. Anammox bacteria showed good attachment capacity, with an initial adhesion phase lasting for 5-7 days at the different flow rates tested (Reynolds numbers 54, 63, 188 and 400). A four-parameter model was developed and the experimental data fitted well into the model. The pre- sence of $5 \mathrm{~g} / \mathrm{L}$ of each of the two salts favoured the formation of Anammox biofilm. The effects of $\mathrm{CaCl}_{2}$ were stronger than those caused by $\mathrm{NaCl} .15 \mathrm{~g} / \mathrm{L}$ of $\mathrm{NaCl}$ was detrimental for the biofilm, probably due to an inhibitory effect.
\end{abstract}

Keywords Anammox $\cdot$ Attachment rate $\cdot$ Biofilms $\cdot$

Mathematical modelling $\cdot$ Shear stress

\section{Introduction}

Anammox biomass is characterised by its long duplication time and low biomass yield [1]. This is an advantage because the production of surplus sludge is reduced; however, it also implies that the process must be operated in reactors with very good sludge retention. Some of the systems used to improve biomass retention are based on biofilm reactors, either with moving bed carriers [2-6] or fixedbed systems [7-10].

The formation of bacterial biofilms must, necessarily, begin with the adhesion of a small number of bacterial cells to a surface [11]. Microbial adhesion has been described in the literature by means of Derjaguin-Landau-Verwey- Overbeek (DLVO) theory, developed by Derjaguin and Landau [12] and 
Verwey and Overbeek [13]. According to this theory, the net interaction force arises from the balance between attraction forces (van der Waals type) and electrostatic double-layer forces, which are in general repulsive. The increase of the ionic strength of the liquid medium can reduce this electrostatic repulsion by com- pressing the double layer, thus an increase of the salinity can favour the biofilm formation.

Apart from DLVO forces, other interactions can play a role in the adhesion process, such as hydrophobic interactions in aqueous medium. Moreover, bacteria are capable of producing and excreting polymeric metabolites. Extending chains of polymers attached to cells can interact with the surface, holding the cells near the liquid-solid interface (polymer bridging) and favouring the adhesion [14]. The existence and properties of external appendages can also have a strong influence in the adhesion and growth of the biofilm. Therefore, the rate of adhesion depends not only on the surface type but also of the ability of the bacteria (or consortium) to attach.

An important factor to be considered is the fluid motion, which can have two opposite effects on biofilm formation. An increase in fluid velocity increases the shear stress exerted on the deposited microorganisms and this can cause the detachment and also the decrease of bacterial activity when microorganisms are not highly resistant to shear stress (i.e. Anammox organisms $[15,16]$ ). On the other hand, higher fluid velocities reduce mass transfer resistance between the bulk liquid and the biofilm, thus a higher biofilm growth can also occur.

The presence of inorganic ions may also affect microbial attachment to surfaces. Fernández et al. [5] have reported that high concentrations of $\mathrm{NaCl}$ can promote the granulation of Anammox biomass, which can be considered as a form of biofilm without support material. These authors also reported that Anammox organisms are relatively resistant to high salinity, and $\mathrm{NaCl}$ concentrations up to $10 \mathrm{~g} / \mathrm{L}$ were not significantly affecting Anammox activity. Besides, Kartal et al. [17] obtained similar results and reported that freshwater Anammox bacteria could adapt to $\mathrm{NaCl}$ concentrations as high as $30 \mathrm{~g} / \mathrm{L}$.

About the effects caused by the presence of divalent cations such as $\mathrm{Ca}^{2+}$ they are well known as promoters of anaerobic biomass granulation [18]. Divalent cations can form bridges between negatively charged groups on cell surfaces and the support material and they can also link exo-cellular polymers [19, 20].

The use of dynamical methods to study bacterial biofilm formation allows the observation of the adhesion phase. The maximum adhesion capacity of each bacterial strain is related with the ability of the cells to form a biofilm [21]. Moreover, the results of the dynamical studies could be employed to develop a model useful to derive predictions about the growth of the biofilm [22]. Finally, the knowledge about the formation and properties of Anammox biofilms could be valuable in the design and operation of attached biomass reactors. Therefore, the objective of this work was to study the ability of the Anammox biomass to form biofilms under different conditions of shear stress and under the presence of salts.

\section{Materials and methods}

In order to monitor the growth of the biofilm along time, a mechatronic surface sensor (MSS) was utilised $[23,24]$. The working principle of the MSS relies on the fact that the attachment, growth and detachment of biomass on a sup- port can be studied measuring the changes on the surface waves applied through the biofilm. The sensor was com- posed of a polyvinyl chloride (PVC) plate with two electronic instruments 
glued on its outer surface, a piezoelectric actuator and a vibration sensor (accelerometer). The first one generated surface waves which propagated along the plate. The accelerometer was glued on the opposite part of the plate to measure the characteristics of the waves after they propagated through the plate. From this data, the associated software assessed all the wave parameters that can be correlated with the biofilm build-up, in particular the variation of the amplitude. The MSS device was inserted into a semi-cylindrical flow cell (internal diameter $=30 \mathrm{~mm}$; equivalent hydraulic diameter $=18.3 \mathrm{~mm}$ ), similar to the one described by Pereira et al. [25] The flow cell had a height of $1.07 \mathrm{~m}$ and an internal volume about $380 \mathrm{~mL}$. It contained six removable sample collectors with a PVC plate (inner side) of about 1.9 $\mathrm{cm}^{2}$ to take periodical samples of the biofilm. The specific mass of biofilm was periodically measured in terms of volatile suspended solids (VSS) per unit area by mechanically removing the biofilm from the PVC plates. A calibration of the MSS was performed for each experiment to find the relationship between the specific mass of biofilm and the amplitude of the vibration measured by the sensor. This relationship was assumed to be linear according to Pereira et al. [26].

In order to reduce the noise of the signal, two statistical tools were employed. First, the 24 measurements corresponding to each day were used to calculate a daily aver- age. The second step was to use a weighted moving average (WMA), a widely used tool for cleaning and smoothing sensor data [27]. Five points were used in each case to calculate the average, two before and two after the central point. This central point had twice the weight of each other four points.

The processed data were fitted (Solver, Microsoft Excel) into two models for biofilm development. The first (Eq. 1) was developed by Melo and Vieira [22] to describe the evolution of Pseudomonas fluorescens biofilms. It is a relatively simple two-parameter model which considered both growth and detachment processes.

$$
m_{\mathrm{b}}=\frac{k_{2}}{k_{3}}\left(1-\mathrm{e}^{-k_{3} \cdot t}\right)
$$

where $m_{\mathrm{b}}$ is the biomass attached $\left(\mathrm{g} \mathrm{VSS} / \mathrm{m}^{2}\right), k_{2}$ is the growth constant $\left(\mathrm{g} \mathrm{VSS} / \mathrm{m}^{2}\right.$ day) and $k_{3}$ is the detachment constant (per day). A more complex four-parameter model (Eq. 2) was developed in this work from the Melo and Vieira [22] model to include the attachment process. Taking into account the low growth rate of the Anammox biomass and the affinity of this kind of microorganisms to attach to different support materials [5], the increase of biofilm thickness by attachment could be significantly compared to the one caused by biomass growth. This initial attachment was represented as a process with a rate which exponentially decreases with the time, thus its relative importance was high during the formation of the biofilm and lower afterwards. It was modelled with two additional kinetic constants $\left(k_{0}\right.$ and $k_{1}$ ) representing the maximum rate of attachment and the kinetics of decay of the attachment process.

$$
m_{\mathrm{b}}=\frac{k_{0}}{k_{3}-k_{1}}\left(\mathrm{e}^{-k_{1} \cdot t}-\mathrm{e}^{-k_{3} \cdot t}\right) \frac{k_{2}}{k_{3}}\left(1-\mathrm{e}^{-k_{3} \cdot t}\right)
$$


where $m$ is the biomass attached $\left(\mathrm{g} \mathrm{VSS} / \mathrm{m}^{2}\right), k\left(\mathrm{~g} \mathrm{VSS} / \mathrm{m}^{2}\right.$ day) and $k_{1}$ (per day) are constants related to the attachment rate, $k_{2}$ is the growth constant ( $\mathrm{g} \mathrm{VSS} / \mathrm{m}^{2}$ day) and $k_{3}$ is the detachment constant (per day).

To study the biofilm formation in the flow cell, an external Sequencing Batch Reactor (SBR) of 1 L of working volume was used. The reaction medium was pumped from the reactor to the bottom of the flow cell and, then, it was recirculated to the reactor. The SBR was operated in cycles of $6 \mathrm{~h}$ distributed in four periods: mixed fill (300 min), mix (30 min), settle (15 min) and draw (15 min). The system (reactor plus flow cell) was operated as a whole, and its Hydraulic Retention Time (HRT) was about 1.2 days. Temperature was controlled at $30{ }^{\circ} \mathrm{C}$ and $\mathrm{pH}$ at 7-8. Complete mixture was achieved by means of a mechanical stirrer at $70 \mathrm{rpm}$. The reactor was inoculated with enriched Anammox biomass $(0.3 \mathrm{~g} \mathrm{VSS} / \mathrm{L}$ with a specific activity about $0.22 \mathrm{~g} \mathrm{~N} / \mathrm{g}$ VSS day) and, due to the low concentration of biomass, it was fed with a synthetic medium at a relatively low nitrogen loading rate of

$0.06 \mathrm{~g} \mathrm{~N} / \mathrm{L}$ day [28]. The performance of the whole reac- tion system (i.e. reactor plus flow cell) was monitored by means of routine $\mathrm{NH}_{4}{ }^{+} \mathrm{NO}_{2}{ }^{-}, \mathrm{NO}_{3}{ }^{-}$and $\mathrm{pH}$ measurements, according to standard methods [29]. The average nitrogen removal of the system was over $90 \%$ along the whole experimental period. These data are not detailed in the "Results and discussion"' because they are not significant for the purposes of this work.

A series of experiments were performed to research the influence of the shear stress and the salinity of the medium (Table 1). Four different flow rates were tested. The lowest flow rate was near to the minimum, necessary to maintain the fluidized conditions of the biomass through the flow cell. The highest was chosen to avoid shear stress inhibition [15]. Regarding salinity tests, two salts were employed, $\mathrm{NaCl}$ and $\mathrm{CaCl}_{2}$. Fernández et al. [5] reported that the presence of $\mathrm{NaCl}$ improved the retention of biomassin Anammox reactors acting as a granulation promoter. Besides, $\mathrm{CaCl} 2$ has been used as granulation promoterin anaerobic digesters[18]. The initial concentration tested in both cases was $5 \mathrm{~g} / \mathrm{L}$, which was supposed not to be significantly inhibitory for the Anammox biomass [5, 17, 30]. Later on, during test 7, a higher concentration of $\mathrm{NaCl}$ was tested. The duration of the experimental runs was in every case at least about 20 days, this means at least about 15 HRTs and more than 1 time of duplication of the biomass [31], which was considered enough to attain a steady state. However, in some of the cases (especially runs 1-3), longer experimental times were necessary to confirm the observed trends. The start of each experimental run was done under transient operation, so as soon as the salinity was changed, the medium was flowing through the flow cell. This strategy was considered better because high salinity promotes strong auto-aggregation of the Anammox biomass [5]. If that phenomenon was happening inside the reactor, the strong and compact granules formed might prevent or reduce the attachment to the sensor and the PVC plates of the flow cell, apart from causing clogging/smashing in the pump. Besides, taking into account the relatively low HRT, the hydraulic steady state was attained in a short time after the perturbation.

\section{Results and discussion}

In order to study the effect of the shear stress, four experiments were performed at different flow rates (Table 1). The results are presented directly in terms of specific mass of biofilm (Fig. 1), calculated with 
the raw data from the MSS and the calibration performed in each case. The initial trend in the four cases was quite similar, with a fast adhesion phase. However, in the latter runs (3 and 4), after the initial quick formation of the biofilm, a maximum thickness value was achieved and later it decreased until a stable value. A similar type of behaviour was observed in runs 5-7, under high salinity (Fig. 2). Data of runs 1 and 2 suggested that the biofilm could not be as mechanically resistant as the biofilm obtained in the rest of the experiments. This may be an explanation for the wave-like shapes observed, probably caused by short detachment/attachment phenomena on some parts of the surface. The final stable state of the biofilm during runs 3 and 4 would agree with the report by Vieira et al. [32], for the properties of biofilms subjected to high shear stress conditions. Besides, Pereira et al. [26] also reported that bio-films formed under high stress are more dense and stable. The experimental results fitted quite well into the Melo and Vieira [22] model (Eq. 1) for low Reynolds numbers (runs 1 and 2), but this simple model was not able to explain the behaviour of the biofilms for higher stress conditions (runs 3-7). Since the low growth rate of Anammox microorganisms does not justify this initial increase of the biofilm thickness, it could be attributed to the attachment ability of the biomass. For this reason, when the second model was employed (Eq. 2), it was able to appropriately explain the behaviour of the biofilm and the experimental data fitted well into it.

The values of the coefficients were obtained for each operational condition (Table 2). The reciprocal of $k_{3}$ is related to the biofilm resistance to detachment. In the case of the experiments done at different salinity conditions and similar Reynolds numbers (runs 3, 5, 6 and 7), the mini- mum value of $k_{3}$ was obtained at salt concentrations of $5 \mathrm{~g} / \mathrm{L}$. This would indicate that these salinity conditions are optimal to promote the biofilm formation. The increase of $k_{3}$ value when the system was operated at $15 \mathrm{~g} \mathrm{NaCl} / \mathrm{L}$ (run 7) is probably due to the inhibitory effect of $\mathrm{NaCl}$ on the Anammox activity [33]. Dapena-Mora et al. [30] found that $\mathrm{NaCl}$ concentrations higher than $8.8 \mathrm{~g} / \mathrm{L}$ could have an inhibitory effect over the Anammox activity when the biomass was not acclimatised. These authors also reported a $\mathrm{IC}_{50}$ (concentration causing $50 \%$ of inhibition of the Anammox activity) of $13.5 \mathrm{~g} \mathrm{NaCl} / \mathrm{L}$, which agrees with the detrimental effects observed during run 7 .

Comparing runs 5 and 3, done under the same shear stress (Figs. 1, 2), but with and without $\mathrm{NaCl}$, respectively, the behaviour obtained was similar. An initial very fast attachment phase was observed, followed by a phase with some instability of the biofilm and partial detachment. Finally, the biofilm achieved a relative stability. The main difference between both experiences was that the initial attachment rate and the final specific biofilm mass observed were much higher in the case of run 5 . This fact could be attributed in the presence of sodium chloride.

According to the cation bridging theory proposed by Schmidt and Ahring [19] and Hulsoff Pol et al. [20] and taking into account that sodium cation is monovalent, it cannot form bridges between the cell and the support sur- face. Thus, its effects should be explained by other mechanism. One plausible hypothesis could be based on the fact that higher ionic strength of the liquid medium can help to reduce electrostatic double-layer repulsion forces, according to DLVO theory. The ionic strength of the medium before salt addition was about $0.02 \mathrm{M}$, and the increase caused by the addition of $\mathrm{NaCl}$ was about $0.09 \mathrm{M}$.

Morisaki and Tabuchi [34] tested several bacterial species (i.e. Pseudomonas syringae, Paracoccus denitrificans, Staphylococcus epidermidis) and they reported that the rate of attachment to a surface increased with the ionic strength until a maximum, and then plateaued. The same behaviour was reported by Poortinga et al. [35]. Furthermore, Zhu et al. [36] reported that deposition of extracellular poly-meric 
substances (EPS) increased with increasing ionic strength, which confirmed the prediction by DLVO theory. EPS play an important role in cell aggregation, cell adhe-sion, and biofilm formation [37]. Thus, deposition of EPS can be the first step of the microbial adhesion when a biofilm is formed. Apart from this phenomenon, some incorporation of the salt into the biofilm was observed and swelling phenomena could take place. In fact, the biofilm samples taken during run 5 had an average of $37 \%$ of inorganics, compared to $\backslash 1 \%$ for the samples taken during the first four runs when no salt was added.

The behaviour of the biofilm in presence of calcium chloride (run 6) was similar to the tests without salts, focusing on the first fast attachment phase (Figs. 1, 2). However, an important difference was observed in this case. After this attachment phase, which reached about $21 \mathrm{~g} \mathrm{VSS} / \mathrm{m}^{2}$, the biofilm (Fig. 2) was stable and no significant detachment was observed. Therefore, the effect of this salt in stabilising a thicker biofilm was much more important than the observed with sodium chloride. This can be probably explained by cationic bridging $[19,20]$ together with the mechanisms previously explained for sodium chloride. The increase of ionic strength of the medium caused by the addition of $\mathrm{CaCl}_{2}$ was about $0.14 \mathrm{M}$, higher than the caused by the same concentration of $\mathrm{NaCl}$. Furthermore, Sobeck and Higgins [38] reported that cationic bridging theory is the one which best described the role of

$\mathrm{Ca}^{2+}$ in bioflocculation. It is important to remark that the incorporation of calcium chloride into the biofilm matrix was happening in a bigger extent than the corresponding to $\mathrm{NaCl}$ during run 5 and biofilm samples had an average of $53 \%$ of inorganics. Despite salinity being positive for the formation and stabilisation of the biofilm, this incorporation of salt into the biofilm could be detrimental for the activity of the Anammox biomass, especially in the case of precipitation phenomena [39].

Finally, in the case of run 7 , despite the fast attachment phase was again observed, its maximum was significantly lower than the observed during the previous six experiments. After this maximum was reached, the biomass attached continuously decreased and, at day 20, the biofilm mass was almost negligible. This behaviour might have been caused by inhibition of the Anammox biomass. However, that suspected inhibition was not causing a decrease of the removal performance of the system, which remained over $90 \%$.

\section{Conclusion}

Anammox bacteria have a good capacity to attach and to form biofilms under the shear stress conditions tested. The observed initial adhesion phase was fast and, in general, lasted for 5-7 days.

The presence of salts favoured the formation of Anammox biofilm probably because of reduction of electrostatic repulsion forces. The effects of the $\mathrm{CaCl}_{2}$ were stronger than those caused by $\mathrm{NaCl}$ due to the concurrent effect of divalent cationic bridging. Incorporation of inorganics into the biofilm was observed in both cases, but it was more important with $\mathrm{CaCl}_{2}$. This effect can be potentially negative for the activity of the biomass.

A four-parameter model has been developed to represent the formation of Anammox biofilms under different conditions of shear stress and salinity.

\section{Acknowledgments}

This work was funded by the project Togransys (CTQ2008-06792-C02-01) and the NOVEDAR_Consolider project (CSD2007-00055), both from the Spanish Ministry for Education and Science. 


\section{References}

1. Strous M, Fuerst JA, Kramer EHM, Logemann S, Muyzer G, van de Pas-Schoonen KT, Webb R, Kuenen JG, Jetten MSM (1999) Missing lithotroph identified as new planctomycete. Nature 400(6743):446-449

2. Helmer C, Tromm C, Hippen A, Rosenwinkel KH, Seyfried CF, Kunst S (2001) Single stage biological nitrogen removal by nit- ritation and anaerobic ammonium oxidation in biofilm systems. Water Sci Technol 43(1):311-320

3. Gaul T, Marker S, Kunst S (2005) Start-up of moving bed biofilm reactors for deammonification: the role of hydraulic retention time, alkalinity and oxygen supply. Water Sci Technol 52(7):127-133

4. Szatkowska B, Cema G, Plaza E, Trela J, Hultman B (2007) A one-stage system with partial nitritation and Anammox processes in the moving-bed biofilm reactor. Water Sci Technol 55(8-9):19-26

5. Fernández I, Vázquez-Padín JR, Mosquera-Corral A, Campos JL, Méndez R (2008) Biofilm and granular systems to improve Anammox biomass retention. Biochem Eng J 42(3):308-313

6. Jaroszynski LW, Cicek N, Sparlingc R, Oleszkiewicz JA (2012) Impact of free ammonia on anammox rates (anoxic ammonium oxidation) in a moving bed biofilm reactor. Chemosphere 88:188-195

7. Tal Y, Watts JEM, Schreier HJ (2006) Anaerobic ammonium- oxidizing (anammox) bacteria and associated activity in fixed- film biofilters of a marine recirculating aquaculture system. Appl Environ Microbiol 72(4):2896-2904

8. Isaka K, Sumino T, Tsuneda S (2007) High nitrogen removal performance at moderately low temperature utilizing anaerobic ammonium oxidation reactions. J Biosci Bioeng 103(5):486-490

9. Liu C, Yamamoto T, Nishiyama T, Fujii T, Furukawa K (2009) Effect of salt concentration in anammox treatment using non woven biomass carrier. J Biosci Bioeng 107(5):519-523

10. Wang T, Zhang H, Yang F, Li Y, Zhang G (1999) Start-up and long-term operation of the Anammox process in a fixed bed reactor (FBR) filled with novel non-woven ring carriers. Che- mosphere 91(5):669-675

11. Costerton JW (1999) Introduction to biofilm. Int J Antimicrob Agents 11(3-4):217-221

12. Derjaguin B, Landau L (1941) Theory of the stability of strongly charged lyophobic sols and of the adhesion of strongly charged particles in solution of electrolytes. Acta Phisicochimica URSS 14:633-662

13. Verwey EJW, Overbeek JTG (1948) Theory of the stability of lyophobic colloids. Elsevier, Amsterdam

14. Characklis WG, Cooksey KE (1983) Biofilms and microbial fouling. Adv Appl Microbiol 29:93-138

15. Arrojo B, Mosquera-Corral A, Campos JL, Méndez R (2006)

Effects of mechanical stress on Anammox granules in a sequencing batch reactor (SBR). J Biotechnol 123(4):453-463

16. Arrojo B, Figueroa M, Mosquera-Corral A, Campos JL, Méndez R (2008) Influence of gas flow-induced shear stress on the operation of the Anammox process in a SBR. Chemosphere 72:1687-1693

17. Kartal B, Koleva M, Arsov R, van der Star W, Jetten MSM, Strous M (2006) Adaptation of a freshwater anammox population to high salinity wastewater. J Biotechnol 126(4):546-553

18. Tiwari MK, Guha S, Harendranath CS, Tripathi S (2006) Influ- ence of extrinsic factors on granulation in UASB reactor. Appl Microbiol Biotechnol 71(2):145-154

19. Schmidt JE, Ahring BK (1994) Extracellular polymers in gran- ular sludge from different upflow anaerobic sludge blanket (UASB) reactors. Appl Microbiol Biotechnol 42(2-3):457-462

20. Hulsoff Pol LW, de Castro Lopes SI, Lettinga G, Lens PNL (2004) Anaerobic sludge granulation. Water Res 38(6):13761389

21. Cerca N, Pier GB, Oliveira R, Azeredo J (2004) Comparative evaluation of coagulase-negative staphylococci (CoNS) adher- ence to acrylic by a static method and a parallel-plate flow dynamic method. Res Microbiol 155(9):755-760

22. Melo LF, Vieira MJ (1999) Physical stability and biological activity of biofilms under turbulent flow and low substrate con- centration. Bioprocess Eng 20(4):363-368

23. Pereira A, Rosmaninho R, Mendes J, Melo LF (2006) Monitoring deposit build-up using a novel Mechatronic Surface Sensor (MSS). Food Bioprod Process 84(4):366-370

24. Pereira A, Mendes J, Melo LF (2009) Monitoring cleaning-in- place of shampoo films using nanovibration technology. Sens Actuators B 136(2):376-382

25. Pereira MO, Mor'in P, Vieira MJ, Melo LF (2002) A versatile

reactor for continuous monitoring of biofilm properties in labo- ratory and industrial conditions. Lett Appl Microbiol 34(1):2226 
26. Pereira A, Mendes J, Melo LF (2008) Using nanovibrations to monitor biofouling. Biotechnol Bioeng 99(6):1407-1415

27. Zhuangt Y, Chen L, Wang XS, Lian J (2007) A weighted moving average-based approach for cleaning sensor data. In: Proceedings of 27 th international conference on distributed computing sys- tems, 2007. ICDCS'07. Toronto, Canada, 25-27 June 2007. IEEE

28. Dapena-Mora A, van Hulle S, Campos JL, Méndez R, Vanrol- leghem PA, Jetten MSM (2004) Enrichment of Anammox bio- mass from municipal activated sludge: experimental and modelling results. J Chem Technol Biotechnol 79(12):1421-1428

29. APHA (1998) Standard methods for the examination of water and wastewater, 20th edn. American Public Health Association, Washington, DC

30. Dapena-Mora A, Fernández I, Campos JL, Mosquera-Corral A, Méndez R, Jetten MSM (2007) Evaluation of activity and inhi- bition effects on Anammox process by batch tests based on the nitrogen gas production. Enzyme Microb Technol 40(4):859-865

31. Strous M, Heijnen JJ, Kuenen JG, Jetten MSM (1998) The sequencing batch reactor as a powerful tool for the study of slowly growing anaerobic ammonium-oxidizing microorganisms. Appl Microbiol Biotechnol 50(5):589-596

32. Vieira MJ, Melo LF, Pinheiro MM (1993) Biofilm formation: hydrodynamic effects on internal diffusion and structure. Bio- fouling 7:67-80

33. Jin RC, Yang GF, Yu JJ, Zheng P (2012) The inhibition of the Anammox process: a review. Chem Eng J 197:67-79

34. Morisaki A, Tabuchi H (2009) Bacterial attachment over a wide range of ionic strengths. Colloids Surf B 74(1):51-55

35. Poortinga AT, Bos R, Busscher HJ (2001) Electrostatic inter- actions in the adhesion of an ion-penetrable and ion-impenetrable bacterial strain to glass. Colloids Surf B 20(2):105-117

36. Zhu P, Long G, Ni J, Tong M (2009) Deposition kinetics of extracellular polymeric substances (EPS) on silica in monovalent and divalent salts. Environ Sci Technol 43(15):5699-5704

37. Dogsa I, Kriechbaum M, Stopar D, Laggner P (2005) Structure of bacterial extracellular polymeric substances at different pH val- ues as determined by SAXS. Biophys J 89(4):2711-2720

38. Sobeck DC, Higgins MJ (2002) Examination of three theories for mechanisms of cation-induced bioflocculation. Water Res 36(3):527-538

39. Trigo C, Campos JL, Garrido JM, Méndez R (2006) Start-up of the Anammox process in a membrane bioreactor. J Biotechnol 126(4):475-487 

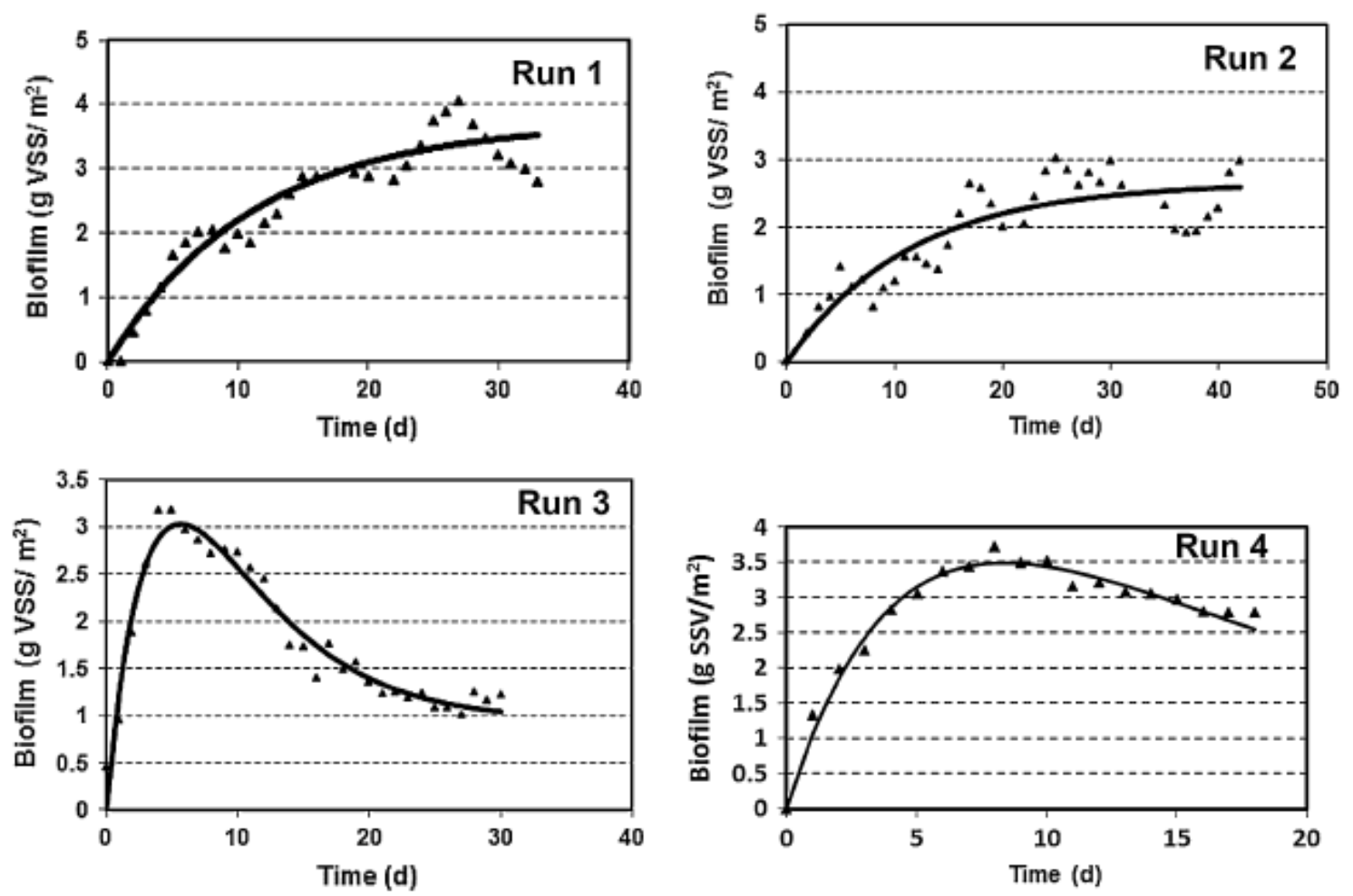

Fig. 1 Biofilm development during runs 1-4, under no saline conditions (filled triangles indicate experimental data; dashed line indicates model)
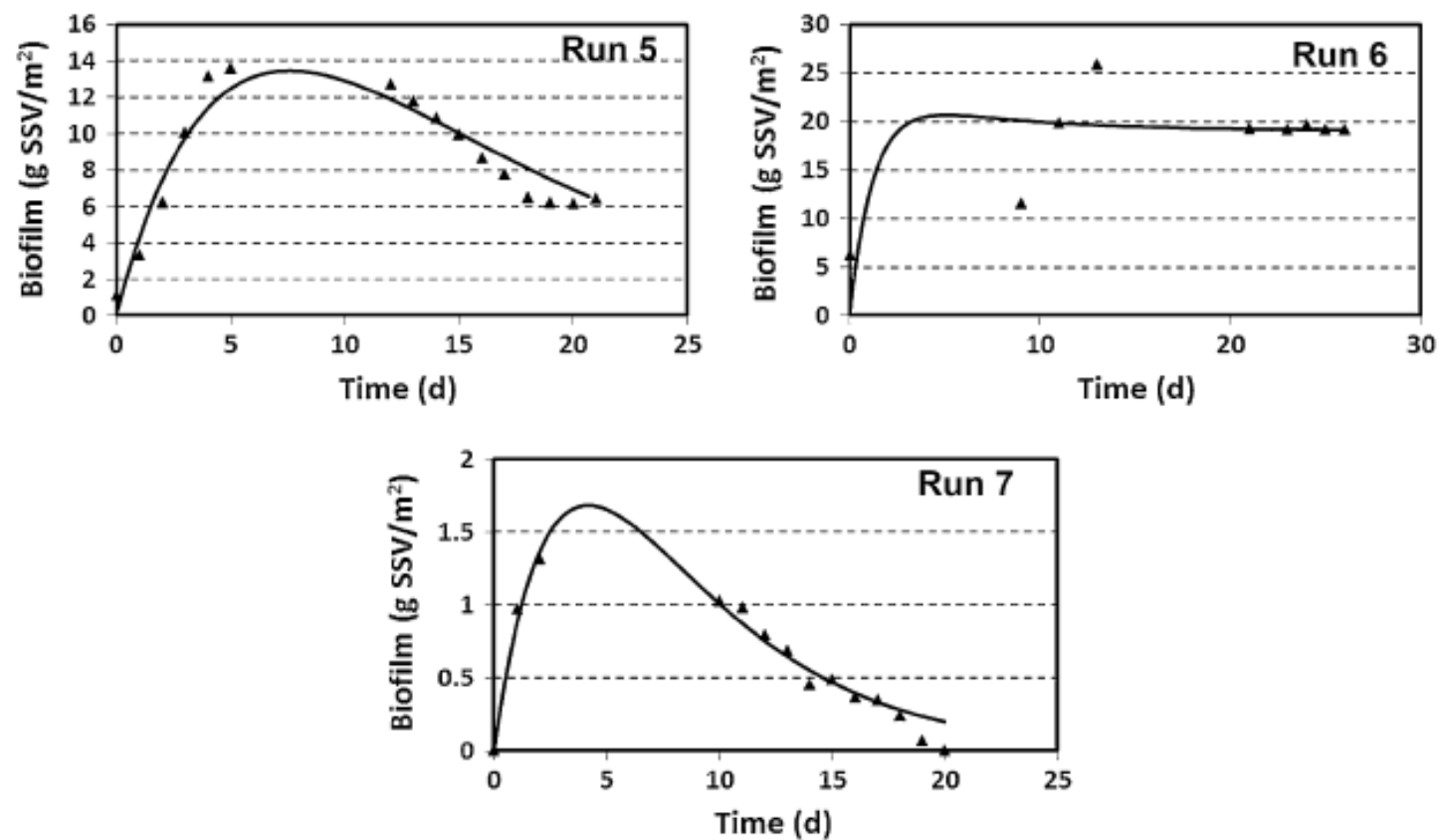

Fig. 2 Biofilm development during runs 5-7, under saline conditions (filled triangles indicate experimental data; dashed line indicates model) 
Table 1 Experimental strategy

\begin{tabular}{lllll}
\hline Run & $\begin{array}{l}\text { Flow } \\
\text { rate } \\
(\mathrm{L} / \mathrm{h})\end{array}$ & $\begin{array}{l}\text { Surface } \\
\text { velocity } \\
(\mathrm{m} / \mathrm{h})\end{array}$ & $\begin{array}{l}\text { Reynolds } \\
\text { number }\end{array}$ & $\begin{array}{l}\text { Salt } \\
\text { concentration } \\
(\mathrm{g} / \mathrm{L})\end{array}$ \\
\hline 1 & 7.3 & 8.3 & 54 & 0 \\
2 & 8.4 & 9.6 & 63 & 0 \\
3 & 25.2 & 28.7 & 188 & 0 \\
4 & 55.3 & 63.0 & 400 & 0 \\
5 & 25.2 & 28.7 & 188 & $5(\mathrm{NaCl})$ \\
6 & 25.2 & 28.7 & 188 & $5(\mathrm{CaCl})$ \\
7 & 27.7 & 31.5 & 200 & $15\left(\mathrm{NaCl}^{2}\right)$ \\
\hline
\end{tabular}

Table 2 Coefficient values of the mathematical model and mean squared error (MSE) of each fit

\begin{tabular}{|c|c|c|c|c|c|}
\hline \multirow[t]{2}{*}{ Experiment } & \multicolumn{4}{|l|}{ Coefficient } & \multirow{2}{*}{$\begin{array}{l}\text { MSE } \\
\left(g_{2 S S /} \text { VS }\right. \\
\left.\mathrm{m}^{2} \text { day }\right)^{2}\end{array}$} \\
\hline & $\begin{array}{l}k_{0} \text { (g VSS/ } \\
\mathrm{m}^{2} \text { day) }\end{array}$ & $\begin{array}{l}k_{1} \text { (per } \\
\text { day) }\end{array}$ & $\begin{array}{l}k_{2} \text { (g VSS/ } \\
\mathrm{m}^{2} \text { day) }\end{array}$ & $\begin{array}{l}k_{3} \text { (per } \\
\text { day) }\end{array}$ & \\
\hline 1 & - & - & 0.33 & 0.09 & 0.11 \\
\hline 2 & - & - & 0.23 & 0.09 & 0.11 \\
\hline 3 & 1.33 & 0.20 & 0.19 & 0.20 & 0.03 \\
\hline 4 & 1.10 & 0.08 & 0.19 & 0.09 & 0.02 \\
\hline 5 & 4.81 & 0.14 & 0.01 & 0.13 & 0.95 \\
\hline 6 & 15.04 & 0.80 & 3.06 & 0.16 & 16.9 \\
\hline 7 & 1.10 & 0.28 & 0.00 & 0.20 & 0.01 \\
\hline
\end{tabular}

